\title{
Why I . . . garden
}

Peter Brennan, consultant oral and maxillofacial surgeon and honorary professor of surgery, talks to Helen Jones about how getting out in the garden helps him to switch off from work

\section{Helen Jones}

London, UK

In addition to a busy NHS job and several national commitments, Peter Brennan has recently received a $\mathrm{PhD}$ and is lead editor of the forthcoming Gray's Surgical Anatomy. "All of this means that I need something else in my life so that when I come home and shut the door I can try and forget about work," he says.

Brennan began gardening when he moved to his current home on the outskirts of a Hampshire market town about 10 years ago. He is, in his own words, very much an amateur.

"I don't know what half the plants in the garden are," he says. "If I see a nice shrub I'll buy it, but then forget its name." But being a non-expert is the point, he says. "With surgery we have to know so much and there are all sorts of work pressures. The joy of gardening is that I know very little and there's no pressure - well, except perhaps being told off for pruning the wrong way."

He adds, "I can go into the garden and drift away, sit and listen to the birds with a glass of wine, and put food out for the six hedgehogs that visit every evening. It's an absolute joy."

Brennan says that while a surgeon has to be good with their hands, he is very mediocre at gardening. "I don't want to be good at anything else, and won't be taking any plants or flowers to competitions-why do that when medicine itself is such a competitive profession? No, gardening allows me to let go without the worry of treating patients and managing surgical complications."
As well as tending to his plants, Brennan makes compote from his Bramley apples and is now considering getting a hive of bees. "I would like to see if I can turn my hand to something else," he says. "Bees would be a great project and would also help the environment," he says.

As well as being an enjoyable pastime, gardening has had a positive impact on Brennan's work-life balance. "I switch off at weekends now-I never used to," he says. "If we make time for ourselves and spend some of it in the garden, then we can go back to work refreshed and energised."

He adds, "If you feel good in yourself, then you perform better at work. If you just keep going on that hamster wheel it can make you inefficient and raises the risk of burnout and depression."

\footnotetext{
How to make the change

- Look at other people's gardens and visit garden centres to get an idea of what you like and the sort of plants you may want to grow

- Buy a simple beginner's book

- Be prepared for trial and error-and for failure

- Don't put yourself under too much pressure-just enjoy it and have fun Don't aim to win any Royal Horticultural Society prizes

- Get the right tools for the job-a proper hedge trimmer is better than shears

- If you can't do it all, and you can afford it, get help once a month with the more labour intensive tasks, such as trimming the hedges.
} 